\title{
Research on the selection mechanism of the agent based on AHP- fuzzy comprehensive evaluation method
}

\author{
Qingguo $\mathrm{Hu}^{\mathrm{a}}$, Yao Zhong ${ }^{\mathrm{b}}$, Zheng $\mathrm{Wang}^{\mathrm{c}}$ and Jianpeng $\mathrm{Wu}^{\mathrm{d}}$ \\ School of Traffic and Transportaion Engineering,Changsha University of Science \& Technology \\ Changsha 410014, China \\ huqg@126.com,549389589@qq.com,419573597@qq.com,627966872@qq.com
}

\begin{abstract}
Keywords: Agent construction system; AHP; Fuzzy comprehensive evaluation
\end{abstract}
Abstract. In view of the problem of the subjectivity and some factors are hard to quantify in the process of selecting the agent for government investment projects. Draw on relevant research results,analysis of the factors affecting the comprehensive ability of the agent and establish a comprehensive ability evaluation system of the agent,. AHP- fuzzy comprehensive evaluation method is used to quantify and analyze the influencing factors. The results show that: the AHP-fuzzy comprehensive evaluation method is suitable for the selection of the agent, which can greatly improve the efficiency and the scientific nature of the comprehensive ability of the construction unit.

\section{Introduction}

Agent construction system refers to the system of the agent through the tender form of selection approved, bear the project's financial management, organization、 construction work and transfer to the use of units after the project completed ${ }^{[1]}$.Yao Yao ${ }^{[2]}$,Peng Lv $^{[3]}$, Chi Qian ${ }^{[4]}$ based on the theory of game theory, the paper analyzes and studies the government regulation, contract optimization and moral hazard. Although there are many researches on the agent construction system, the research on how to choose the agent is less. AHP-fuzzy comprehensive evaluation method is a combination of AHP and fuzzy comprehensive evaluation method ${ }^{[5]}$, which has been widely used in various fields. In this paper, a comprehensive evaluation system is established, and the AHP- fuzzy comprehensive evaluation method is adopted to quantify and analyze the influencing factors, so as to select the most suitable for the construction of the unit.

\section{Determination of index weight}

(1) Establish hierarchical structure. To determine the impact factors of the evaluation object and to construct the evaluation index system.

(2) Structure judgment matrix. Experts using 1-9 ratio scale method to obtain the importance of $\mathrm{C}$ and $\mathrm{G}$ layer factors and get table $1 \mathrm{C}-\mathrm{G}$ judgment matrix.

Table $1 \mathrm{C}-\mathrm{G}$ judgment matrix

\begin{tabular}{|c|cccc|}
\hline $\mathrm{C}_{\mathrm{k}}$ & $\mathrm{G}_{1}$ & $\mathrm{G}_{2}$ & $\ldots$ & $\mathrm{G}_{\mathrm{n}}$ \\
\hline $\mathrm{G}_{1}$ & 1 & $\mathrm{~L}_{12}$ & $\ldots$ & $\mathrm{L}_{1 \mathrm{n}}$ \\
$\ldots$ & $\ldots$ & $\ldots$ & $\ldots$ & $\ldots$ \\
$\mathrm{G}_{\mathrm{n}}$ & $\mathrm{L}_{\mathrm{n} 1}$ & $\mathrm{~L}_{\mathrm{n} 2}$ & $\ldots$ & 1 \\
\hline
\end{tabular}

$\mathrm{C}_{\mathrm{k}}=\mathrm{G}_{\mathrm{i}} / \mathrm{G}_{\mathrm{j}}$, which shows that the relative importance of $G_{i}$ and $G_{j}$ is the relative importance of the overall evaluation of $\mathrm{C}_{\mathrm{k}}$. The judgment matrix is characterized by a diagonal value of 1 , which means that each factor is equal to its importance.

(3) Solve the relative weight of the index. 
a. Calculate the product of each element of the judgment matrix $M_{i}=\prod_{j=1}^{m} L_{i j}(\mathrm{i}=1,2, \ldots, \mathrm{m})$

b. Calculate $\mathrm{m}$ Mi Times Square $\mathrm{C}_{\mathrm{i}}=\sqrt[m]{m_{\mathrm{i}}} \quad(\mathrm{i}=1,2, \ldots, \mathrm{m})(1.2)$

c. Normalized processing of $\mathrm{C}$ vector. Make $\mathrm{W}_{\mathrm{i}}=\mathrm{C}_{\mathrm{i}} / \sum_{\mathrm{i}=1}^{\mathrm{m}} \mathrm{C}_{\mathrm{k}}, \quad(\mathrm{i}=1,2, \ldots, \mathrm{m})$, the maximum characteristic $\lambda_{\max }$ value of the corresponding column vector $\mathrm{W}=\left[\begin{array}{ll}w_{1} & w_{2}, w_{3}, \ldots, w_{\mathrm{m}}\end{array}\right]^{T}$.

d. Calculation of the maximum eigenvalues of G $\lambda_{\max }=\frac{1}{\mathrm{~m}} \sum_{i=1}^{m} \frac{(G W)_{\mathrm{i}}}{w_{i}}$

(4) Consistency test.

a. Put $\lambda_{\max }$ into the formula 1.3 respectively, $\quad \mathrm{CI}=\frac{\lambda_{\max }-\mathrm{m}}{\mathrm{m}-1}$

b. According to table 2 find out the corresponding average random consistency ratio RI. Table 2 Mean random consistency index RI

\begin{tabular}{c|c|c|c|c|c|c|c|c|c}
\hline Order $\mathrm{n}$ & 1 & 2 & 3 & 4 & 5 & 6 & 7 & 8 & 9 \\
\hline RI & 0.00 & 0.00 & 0.58 & 0.90 & 1.12 & 1.24 & 1.32 & 1.41 & 1.45 \\
\hline
\end{tabular}

c. Calculate the consistency of the proportion of $\mathrm{CR}=\mathrm{CI} / \mathrm{RI} \quad(1.4)$

In general, for the $n \geq 3$ of the judgment matrix, when $C R \leq 0.1$, we believe that the consistency of the judgment matrix can be accepted.On the contrary, it is indicated that the degree of deviation is too large, and it is necessary to revise the judgment matrix until $\mathrm{CR} \leq 0.1$, which can be found to satisfy the consistency test.

\section{Fuzzy comprehensive evaluation}

(1) Establish fuzzy comprehensive relationship matrix.

a. Determine the factor set $F=\left\{F_{1}, \ldots, F_{n}\right)$. Where $m$ is a number of evaluation factors.

b. Let $F_{V}=\left(F_{V 1}, \ldots, F_{V m}\right)$ is a collection of the evaluation grades of the evaluation results of the evaluation factors, $m$ represents the total evaluation level.

c. Establish membership matrix R.

$\mathrm{R}=\left[\begin{array}{l}R \mid F_{1} \\ R \mid F_{2} \\ \ldots \mid \ldots \\ R \mid F_{m}\end{array}\right]=\left[\begin{array}{cccc}r_{11} & r_{12} & \ldots & r_{1 \mathrm{~m}} \\ r_{21} & r_{22} & \ldots & r_{2 \mathrm{~m}} \\ \ldots & \ldots & \ldots & \ldots \\ r_{n 1} & r_{n 2} & \ldots & r_{\mathrm{nm}}\end{array}\right] \begin{aligned} & \text { Which } \mathrm{r}_{\mathrm{ij}} \text { indicates that the } \mathrm{i} \text { has a } \mathrm{F}_{\mathrm{vj}} \text { of } \mathrm{F}_{\mathrm{i}}\left(0<\mathrm{r}_{\mathrm{ij}}<1\right) \text {. } \\ & \text { Thembership degree matrix in which each row is, } \\ & \text { according to the results of the evaluation of single } \\ & \text { press comments set } \mathrm{F}_{\mathrm{V}} \text { of evaluation object factor set } \mathrm{F} \text { of }\end{aligned}$

(2) Single factor analysis. all evaluation information.

Membership degree $\mathrm{C}_{\mathrm{ik}}$ is an important factor in the single factor evaluation, that is the weight of each factor $\mathrm{W}_{\mathrm{IK}} \mathrm{G}_{\mathrm{i}}=\mathrm{C}_{\mathrm{i}} * \mathrm{R}_{\mathrm{i}}=\left(\mathrm{L}_{\mathrm{i} 1}, \mathrm{~L}_{\mathrm{i} 2}, \ldots, \mathrm{L}_{\mathrm{im}}\right),(\mathrm{i}=1,2, \ldots \mathrm{k})$.

(3) Comprehensive evaluation of multiple factors.

Weight vector $C=\left(C_{1}, C_{2}, \ldots, C_{k}\right)$, the comprehensive evaluation matrix $R=\left(G_{1}, G_{2}, \ldots\left(G_{k}\right)^{T}=\right.$ $\left(\mathrm{L}_{\mathrm{ij}}\right)_{\mathrm{k} * \mathrm{~m}}$. Comprehensive evaluation vector $\mathrm{G}=\mathrm{C} * \mathrm{R}=\left(\mathrm{L}_{1} \cdot \mathrm{L}_{2}, \ldots \mathrm{L}_{\mathrm{m}}\right)$.

(4) Calculation of comprehensive evaluation $\mathrm{Q}$.

The comprehensive evaluation of the value of $Q=G^{*} V^{T}$. 


\section{Case Application}

(1) Structure Judgment Matrix. The multiple comparison between the target layer and the standard layer factor by the experts, establish AHP's judgment matrix distribution weight.

Table 3 Comprehensive Evaluation of judgment matrix and weight

\begin{tabular}{cccccc}
\hline $\mathrm{C}$ & $\mathrm{G}_{1}$ & $\mathrm{G}_{2}$ & $\mathrm{G}_{3}$ & $\mathrm{G}_{4}$ & Weight $(\omega)$ \\
\hline $\mathrm{G}_{1}$ & 1 & 4.83 & 2.95 & 3.84 & 0.51 \\
$\mathrm{G}_{2}$ & 0.21 & 1 & 0.31 & 0.36 & 0.07 \\
$\mathrm{G}_{3}$ & 0.34 & 3.25 & 1 & 2.55 & 0.27 \\
$\mathrm{G}_{4}$ & 0.26 & 2.79 & 0.39 & 1 & 0.15 \\
\hline
\end{tabular}

Table 4 The judgement matrix and weight of the Construction organization plan

\begin{tabular}{cccccccc}
\hline $\mathrm{G}_{1}$ & $\mathrm{~L}_{1}$ & $\mathrm{~L}_{2}$ & $\mathrm{~L}_{3}$ & $\mathrm{~L}_{4}$ & $\mathrm{~L}_{5}$ & $\mathrm{~L}_{6}$ & Weight $(\omega 1)$ \\
\hline $\mathrm{L}_{1}$ & 1 & 1.86 & 2.84 & 1.93 & 2.84 & 3.26 & 0.31 \\
$\mathrm{~L}_{2}$ & 0.54 & 1 & 2.88 & 1.59 & 1.820 & 2.494 & 0.22 \\
$\mathrm{~L}_{3}$ & 0.35 & 0.35 & 1 & 1.92 & 2.205 & 2.043 & 0.16 \\
$\mathrm{~L}_{4}$ & 0.52 & 0.63 & 0.52 & 1 & 1.953 & 2.806 & 0.15 \\
$\mathrm{~L}_{5}$ & 0.5 & 0.55 & 0.45 & 0.51 & 1 & 1.756 & 0.09 \\
$\mathrm{~L}_{6}$ & 0.31 & 0.40 & 0.49 & 0.36 & 0.569 & 1 & 0.07 \\
\hline
\end{tabular}

Table 5 The judgement matrix and weight of the project management institutions

\begin{tabular}{ccccc}
\hline $\mathrm{G}_{2}$ & $\mathrm{~L}_{7}$ & $\mathrm{~L}_{8}$ & $\mathrm{~L}_{9}$ & Weight $(\omega 2)$ \\
\hline $\mathrm{L}_{7}$ & 1 & 1.24 & 3.36 & 0.48 \\
$\mathrm{~L}_{8}$ & 0.81 & 1 & 2.32 & 0.37 \\
$\mathrm{~L}_{9}$ & 0.30 & 0.43 & 1 & 0.15 \\
\hline
\end{tabular}

Table 6 The judgement matrix and weight of the market reputation

\begin{tabular}{cccccc}
\hline $\mathrm{G}_{3}$ & $\mathrm{~L}_{10}$ & $\mathrm{~L}_{11}$ & $\mathrm{~L}_{12}$ & $\mathrm{~L}_{13}$ & Weight $(\omega 3)$ \\
\hline $\mathrm{L}_{10}$ & 1 & 2.12 & 3.15 & 4.69 & 0.44 \\
$\mathrm{~L}_{11}$ & 0.47 & 1 & 1.97 & 3.79 & 0.33 \\
$\mathrm{~L}_{12}$ & 0.32 & 0.51 & 1 & 2.88 & 0.15 \\
$\mathrm{~L}_{13}$ & 0.21 & 0.26 & 0.35 & 1 & 0.08 \\
\hline
\end{tabular}

(2) Calculate the weight of the target layer and the standard layer. (See table 3-6)

(3) Test the consistency.

Table 7 The consistency check of the jud gment matrix and the level of each layer

\begin{tabular}{cccccc}
\hline Index & $\mathrm{C}$ & $\mathrm{G}_{1}$ & $\mathrm{G}_{2}$ & $\mathrm{G}_{3}$ & $\mathrm{G}_{4}$ \\
\hline$\lambda_{\max }$ & 4.172 & 6.2732 & 3.0021 & 4.123 & \\
$\mathrm{CI}$ & 0.0573 & 0.0546 & 0.0011 & 0.041 & \\
$\mathrm{RI}$ & 0.9 & 1.24 & 0.58 & 0.9 & \\
$\mathrm{CR}$ & 0.0637 & 0.0441 & 0.0018 & 0.0456 & 0 \\
\hline
\end{tabular}

From the tables 7,the CR of all index are less than 0.1 ,and the calculation results show that can pass through a one-time inspection. The evaluation index and its weight for the selection mechanism of the Agent,as shown in table 8. 
Table 8 The index system and weight of the selection mechanism of the Agent

\begin{tabular}{|c|c|c|}
\hline $\begin{array}{l}\text { The } \\
\text { target } \\
\text { layer } \\
\text { C }\end{array}$ & $\begin{array}{l}\text { The Standard } \\
\text { layer } \mathrm{G}\end{array}$ & The index layer $\mathrm{L}$ \\
\hline \multirow{14}{*}{ 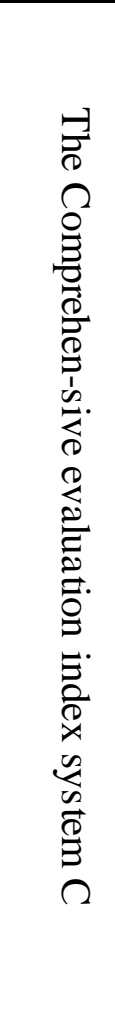 } & \multirow{6}{*}{$\begin{array}{c}\text { The } \\
\text { Construction } \\
\text { organization } \\
\text { plan } \mathrm{G}_{1} \\
(51 \%)\end{array}$} & The quality management system and the measures $\mathrm{L}_{1}(31 \%)$ \\
\hline & & The progress of the project plan and measures \\
\hline & & The use of funds plan and cost control \\
\hline & & The construction scheme and technical measures $\mathrm{L}_{4}(15 \%)$ \\
\hline & & The safety management system and the measures $\mathrm{L}_{5}(9 \%)$ \\
\hline & & The environmental management system and measures $\mathrm{L}_{6}(7 \%)$ \\
\hline & \multirow{3}{*}{$\begin{array}{l}\text { The project } \\
\text { management } \\
\text { institutions } \\
\mathrm{G}_{2}(7 \%)\end{array}$} & $\begin{array}{l}\text { Management personnel qualification and performance } \mathrm{L}_{7} \\
(48 \%)\end{array}$ \\
\hline & & $\begin{array}{l}\text { The organizational form and the allocation of responsibilities } \\
\qquad \mathrm{L}_{8}(37 \%)\end{array}$ \\
\hline & & The project management system $\mathrm{L}_{9}(15 \%)$ \\
\hline & \multirow{4}{*}{$\begin{array}{l}\text { The market } \\
\text { reputation } \\
\mathrm{G}_{3}(27 \%)\end{array}$} & The qualification of enterprise $\mathrm{L}_{10}(44 \%)$ \\
\hline & & The similar project experience $\mathrm{L}^{11}(33 \%)$ \\
\hline & & Project winning situation $\mathrm{L}_{12}(15 \%)$ \\
\hline & & The bad behavior records $\mathrm{L}_{13}(8 \%)$ \\
\hline & $\begin{array}{l}\text { The tender } \\
\text { offer } \mathrm{G}_{4} \\
(15 \%)\end{array}$ & The tender offer $\mathrm{L}_{14}(100 \%)$ \\
\hline
\end{tabular}

(4) Establish fuzzy mathematics model for comprehensive fuzzy evaluation.

a、 $C=\left(G_{1} 、 G_{2} 、 G_{3} 、 G_{4} 、 G_{5}\right)$ representative the Construction organization plan 、 the project management institutions the market reputation , the tender offer.Their evaluation index subset is $\mathrm{G}_{\mathrm{i}}=$ $\left(\mathrm{L}_{\mathrm{ij}}\right), i, j=1,2,3,4,5,6$.

b、 $F v=\left(F_{v_{1}}, F_{v_{2}} 、 F_{v_{3}}, F_{v_{4}}, F_{v_{5}}\right)=(90,80,70 、 60 、 50)$ 。

c、 To determine the weight vector of each level index.

The standard layer: $W_{C}=\left\{\begin{array}{llll}0.51, & 0.07,0.27,0.15\end{array}\right\}$

The index layer: $W_{G 1}=\left\{\begin{array}{llll}0.51, & 0.07, & 0.27, & 0.15\end{array}\right\} \quad W_{G 2}=\left\{\begin{array}{llll}0.48, & 0.37, & 0.15\end{array}\right\}$

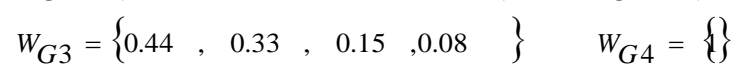

d、 Construction of single factor fuzzy comprehensive evaluation matrix.

$$
\begin{aligned}
\mathrm{R}_{\mathrm{G} 1} & =\left[\begin{array}{ccccc}
3 / 7 & 2 / 7 & 2 / 7 & 0 & 0 \\
2 / 7 & 3 / 7 & 1 / 7 & 1 / 7 & 0 \\
4 / 7 & 2 / 7 & 1 / 7 & 0 & 0 \\
4 / 7 & 3 / 7 & 0 & 0 & 0 \\
2 / 7 & 3 / 7 & 2 / 7 & 0 & 0 \\
4 / 7 & 2 / 7 & 1 / 7 & 0 & 0
\end{array}\right] \quad \mathrm{R}_{\mathrm{G} 2=}=\left[\begin{array}{lllll}
3 / 7 & 2 / 7 & 2 / 7 & 0 & 0 \\
3 / 7 & 3 / 7 & 1 / 7 & 0 & 0 \\
4 / 7 & 2 / 7 & 1 / 7 & 0 & 0
\end{array}\right] \quad \mathrm{R}_{\mathrm{G} 3}=\left[\begin{array}{ccccc}
5 / 7 & 2 / 7 & 0 & 0 & 0 \\
3 / 7 & 3 / 7 & 1 / 7 & 0 & 0 \\
3 / 7 & 4 / 7 & 0 & 0 & 0 \\
4 / 7 & 2 / 7 & 1 / 7 & 0 & 0
\end{array}\right] \\
\mathrm{R}_{\mathrm{G} 4} & =\left[\begin{array}{lllll}
3 / 7 & 3 / 7 & 1 / 7 & 0 & 0
\end{array}\right]
\end{aligned}
$$

e 、 To evaluation the Single factor, and calculation the formula is $G_{i}=W_{G i} * R_{G i}$. $G_{1}=W_{G 1} * R_{G 1}=\left[\begin{array}{lllll}0.438 & 0.351 & 0.180 & 0.031 & 0\end{array}\right]$ 


$$
\begin{aligned}
& G_{2}=W_{G 2} * R_{G 2}=\left[\begin{array}{lllll}
0.451 & 0.338 & 0.211 & 0 & 0
\end{array}\right] \\
& G_{3}=W_{G 3} * R_{G 3}=\left[\begin{array}{lllll}
0.566 & 0.375 & 0.059 & 0 & 0
\end{array}\right] \\
& G_{4}=W_{G 4} * R_{G 4}=\left[\begin{array}{lllll}
0.428 & 0.428 & 0.144 & 0 & 0
\end{array}\right] \\
& \mathrm{R}=\left[\begin{array}{l}
G_{1} \\
G_{2} \\
G_{3} \\
G_{4}
\end{array}\right]=\left[\begin{array}{ccccc}
0.438 & 0.351 & 0.180 & 0.031 & 0 \\
0.451 & 0.338 & 0.211 & 0 & 0 \\
0.566 & 0.375 & 0.059 & 0 & 0 \\
0.428 & 0.428 & 0.144 & 0 & 0
\end{array}\right]
\end{aligned}
$$

f、 To comprehensive evaluate the index of the standard layer factor.

$$
\mathrm{C}=\mathrm{Wc} * \mathrm{R}=\left[\begin{array}{lllll}
0.472 & 0.368 & 0.144 & 0.016 & 0
\end{array}\right]
$$

g、 To calculate comprehensive ability evaluation scores.

$$
\mathrm{Q}=\mathrm{C} * \mathrm{Fv}=\left[\begin{array}{lllll}
0.472 & 0.368 & 0.144 & 0.016 & 0
\end{array}\right] *\left[\begin{array}{lllll}
90 & 80 & 70 & 60 & 50
\end{array}\right]^{\mathrm{T}}=83.96
$$

According to the above method, recommend the highest score of the Agent-construction Unit as the first candidate.

\section{Conclusion}

AHP- fuzzy comprehensive evaluation method is applied to the importance little difference of each index and the situation of the judgment with ambiguity. This method can be applied to the agent construction project of non operational government investment projects, and it can scientifically and objectively determine the weight of each index in the evaluation system of the selection mechanism of the

agent,which can not only avoid the subjectivity of weight determination in the process of judgment and solve the problem that some factors are difficult to quantify, It can greatly improve the efficiency and the scientific nature of the comprehensive ability of the agent.

\section{Acknowledge ment}

This work was financially supported by the Hunan Provincial Department of Education Science Research Key Project (14A007)。

\section{References}

[1] Qi Hui-jiao.Research on the Incentive Mechanisms of Agent Construction System[D].Chong Qi: Chongqing jiaotong University, 2014 (In Chinese)

[2] Yao Yao,Guo Zhi-da.Supervision dynamic game of construction-agent system project[J].Journal of Engineering Management,2014,28(4):52-56. (In Chinese)

[3] Lv Peng,CHEN Xiao-yue.Development and application of multi task principal agent theory[J].EconomicsInformation,2004(8):74-77. (In Chinese )

[4] Qian Chi,LI Qi-ming,WU Wei-wei. The study on contract incentives and constraint conditions of agency construction projects based on game theory[J].Journal of Engineering Management,2013,27(5):18-22. (In Chinese)

[5] Zhang li-na.APPlication of AHP - fuzzy Comprehensive evaluation in assessment of 
eco-ind ustrial park[D]DaLian University of Technology, 2006（In Chinese ） 